\title{
QUANTO CUSTA UMA DIÁRIA? MÉTODOS DE CUSTEIO \\ E PRECIFICAÇÃO NO SETOR HOTELEIRO
}

LEITES, Eduardo Tomedi ${ }^{1}$

ECKERT, Alex ${ }^{2}$

KELLERMANN, Aline Letícia ${ }^{3}$

MECCA, Marlei Salete ${ }^{4}$

VARGAS, Jéssica Santos ${ }^{3}$

\begin{abstract}
RESUMO: Esta pesquisa teve como objetivo verificar quais os métodos de custeio que os hotéis localizados em uma cidade turística gaúcha utilizam para fundamentar suas decisões, bem como os critérios levados em conta na formação do preço de venda. Para tanto, a metodologia utilizada teve como base a elaboração de uma pesquisa descritiva, com predominância quantitativa, e realizada a partir de uma survey. O questionário foi enviado por e-mail para trinta organizações hoteleiras, tendo um retorno de aproximadamente a metade delas. A partir das respostas, foi possível identificar que a maioria das empresas utilizam algum método de custeio, sendo o mais representativo o custeio variável. Quanto a formação do preço de venda, o critério mais empregado pelas empresas é baseado nos custos dos produtos e serviços.
\end{abstract}

Palavras-chave: Custos. Custeio Variável. Preço. Setor hoteleiro.

\section{WHAT IS THE PRICE OF THE ACCOMMODATION? COST METHODS AND PRICE COMPOSITION IN THE HOTEL SECTOR}

\begin{abstract}
SUMMARY: The present research had as objective to verify which methods of costing that the hotels located in a tourist city of the south of Brazil use to base their decisions, as well as the criteria taken into account in the formation of the sale price. To do so, the methodology used was based on the elaboration of a descriptive research, with quantitative predominance, and carried out from a sample survey or survey. The questionnaire was sent by e-mail to thirty hotel organizations, returning approximately half of them. From the answers, it was possible to identify that most companies use some costing method, the most representative variable costing. As for the formation of the sale price, the criterion most used by the companies is based on the costs of the products and services.
\end{abstract}

Keywords: Costs. Variable Costing. Price. Hotel sector.

\section{INTRODUÇÃO}

O cenário político e econômico mundial tem passado por diversas transformações levando as empresas a se depararem com novas realidades que demandam habilidades e esforços de seus administradores na gestão dos empreendimentos, notadamente no segment Universidade de Caxias do Sul - UCSo turístico. De acordo com Beuren (2000), os gestores necessitam conhecer as suas organizações de forma detalhada, assim como o ambiente em que operam, a fim de avaliar o impacto de mudanças que venham a ocorrer, desenvolver soluções eficazes e utilizar a informação para identificar oportunidades e ameaças do setor.

\footnotetext{
${ }^{1}$ Universidade de Caxias do Sul - UCS - Mestre em Ciências Contábeis - UNISINOS

${ }^{2}$ Universidade de Caxias do Sul - UCS - Doutor em Administração - PUCRS/UCS

${ }^{3}$ Universidade de Caxias do Sul - UCS - Bacharel em Ciências Contábeis - UCS

${ }^{4}$ Universidade de Caxias do Sul - UCS - Doutora em Engenharia da Produção - UFSC
} 
Nesse contexto, considerando as atuais condições de competitividade torna-se vital para a sobrevivência das empresas buscar novas alternativas e aprimoramento de suas ferramentas de gestão. Para que elas de diferenciem de seus concorrentes e consolidem seu posicionamento no mercado, a gestão de custos é um dos aspectos relevantes a serem considerados na gestão de um empreendimento. Konraht, Soutes e Alencar (2016) asseveram que a gestão dos custos está também relacionada à questão da Governança Corporativa.

Avaliar se as empresas do setor hoteleiro de uma região turística do Rio Grande do Sul, utilizam um sistema de gestão de custos adequadamente para tomar decisões, evitando, imprevistos, torna-se imperioso.

A presente pesquisa teve como objetivo verificar quais os métodos de custeio utilizados pelos hotéis do município de Bento Gonçalves/RS para fundamentar suas decisões, bem como os critérios levados em conta na formação do preço de venda.

\section{FUNDAMENTAÇÃO TEÓRICA}

Crepaldi (2010) conceitua a Contabilidade de Custos como um procedimento elaborado para captar, calcular e disponibilizar dados a respeito do custo dos serviços e produtos, na qual tem por função fornecer informações ágeis e precisas que possibilitem aos gestores melhores condições para a tomada de decisões. Para Leone (2000), é essencial estabelecer parâmetros para medir o desempenho, elaboração e domínio das atividades a fim de subsidiar a tomada de decisões em diversas esferas administrativas.

Bornia (2002) e Martins (2009) resumem, em duas, as funções da Contabilidade de Custos: o controle das operações e a tomada de decisões. Para Bornia (2002), ao utilizar a ferramenta de controle, os custos podem mostrar onde ocorrem problemas ou situações não-previstas, baseando-se em comparações com padrões e orçamentos. Leone (2000) acrescenta que executar o controle dos custos das operações pode fazer com que os dispêndios diminuam, mediante confronto entre o orçado e o realizado. Em consonância, Martins (2009) afirma que a principal função do Controle é estabelecer estimativas com base em dados ocorridos no passado e acompanhar o comportamento destes parâmetros dentro da expectativa e dos valores pré-estabelecidos.

O processo da tomada de decisão é importante para as empresas, e as informações fornecidas pela contabilidade de custos fornecem subsídios que auxiliam o gestor neste passo. Martins (2009) explica que as informações da contabilidade de custos fornecem uma visão ampliada dos resultados que determinadas medidas podem ocasionar e viabilizam uma mudança de planos no que tange a preços de venda, possibilidades de compras ou fabricação, entre outras decisões.

Uma das principais funções da Contabilidade de Custos é fornecer subsídios para a tomada de decisões, e, em virtude da alta competitividade, as empresas necessitam de ferramentas de custos eficazes para prever e planejar os reflexos de aumento e/ou redução de custos, preços, volumes e mix de produtos (SANTOS, 2011).

Uma das ferramentas mais utilizadas é a margem de contribuição, que aponta em quanto cada produto contribui para o resultado operacional. Conceituada por Martins (2009), a margem de contribuição unitária é o resultado das receitas excluindo-se os Custos e Despesas Variáveis. Essa métrica expõe a capacidade de cada produto gerar lucro, antes do abatimento dos gastos fixos, ou seja, trata-se de um indicador que aponta quanto um produto realmente contribui à empresa, visto que o valor unitário é remanescente após o custo que o originou.

De acordo com Crepaldi (2010), o uso da margem de contribuição auxilia o gestor a escolher em qual produto deve focar a sua atenção para aumentar as vendas e também definir o preço de venda, assim 
como auxilia a empresa a decidir quanto à continuidade ou não de certos produtos, e até mesmo a manutenção de filiais. Crepaldi (2010) ainda acrescenta que conhecer a margem de contribuição dos produtos e serviços é muito útil quando se pretende avaliar alternativas de redução de preços para alavancar o volume das vendas, além de ser necessária para o cálculo do ponto de equilíbrio. Este, por sua vez, tem grande utilidade na avaliação dos negócios, pois indica quando as receitas se igualam aos custos ou despesas totais. Dessa forma, ao atingir o ponto de equilíbrio, a empresa não gera lucro nem prejuízo (CREPALDI, 2010), mas a partir deste, qualquer unidade adicional vendida trará resultados para a empresa.

Bornia (2002) coloca que, em determinados momentos, é útil ao gestor conhecer quantos produtos são necessários produzir e vender para que a empresa consiga cobrir seus custos fixos e variáveis. VanDerbeck e Nagy (2001) assinalam que a análise do ponto de equilíbrio é recomendada quando o administrador precisa conhecer os efeitos que mudanças no volume de vendas exercem sobre os lucros resultantes.

Já a formação do preço de venda é um fator fundamental para a sobrevivência de uma empresa e tem ganho cada vez mais importância na esfera gerencial. Para o Ibracon (1995), a formação do preço de venda é um trabalho essencial, principalmente em relação ao controle administrativo, visto que a economia se comporta de modo instável e estas variações requerem ajustes constantes.

Martins (2009) discorre que, para fixar o preço de venda do produto ou serviço e conhecer os custos que estes incorrem é importante, porém não suficiente: é preciso ter um mix de informações sobre o mercado e sobre a elasticidade da economia para poder fazer a opção mais viável. Para Crepaldi (2010) e Zanella (2010), são três os critérios utilizados na formação do preço de venda: custo, demanda e concorrência. Aliás, a demanda em alguns setores, como o é o caso da hotelaria, está sendo bruscamente afetado pelas questões envolvendo as operações realizadas via internet (ECKERT, 2017).

Zanella (2010) discorre que, para a definição do preço de venda, o custo tem importância primordial, já que indica quanto a empresa deve cobrar para obter o mínimo de lucro. No ramo hoteleiro, o critério de custos mais usual é o mark-up, por ser mais simples e reconhecido. No entanto, apesar de ser um dos métodos mais utilizados pelas empresas, ele apresenta algumas lacunas que podem prejudicar o preço estabelecido, tais como: não considerar a estrutura de mercado no qual a empresa está inserida e a elasticidade do preço da demanda.

\section{METODOLOGIA}

A abordagem do problema do estudo consiste na predominância quantitativa, pois, segundo Beuren (2004), este enfoque caracteriza-se pelo uso de ferramentas estatísticas, tanto na coleta como no tratamento dos dados. Para Richardson (1999), esta abordagem busca garantir a exatidão dos resultados, evitando, assim, possíveis distorções de análise e interpretação.

Com base nos seus objetivos, classifica-se o presente trabalho como uma pesquisa descritiva, uma vez que o objetivo principal é indicar as "características de determinada população ou fenômeno ou, então, o estabelecimento de relações entre variáveis" (GIL, 2002, p. 42). Na concepção de Andrade citado por Beuren (2004), a pesquisa descritiva propõe observar os fatos, registrá-los, analisá-los, classificá-los e interpretá-los, tudo isso sem a interferência do pesquisador.

Em relação aos procedimentos técnicos, foi escolhido o levantamento por amostragem ou survey. Tais pesquisas que procuram descrever com exatidão algumas características de populações designadas são tipicamente representadas por estudos de survey (TRIPODI; FELLIN; MEYER, 1981). 
A coleta de dados para o levantamento foi efetuada via questionário, o qual foi baseado em Silva (2000), sendo este enviado a uma amostra representativa de empreendimentos hoteleiros situados na região de Bento Gonçalves - RS.

\section{REALIZAÇÃO DO ESTUDO}

\subsection{Levantamento e coleta de dados}

O turismo tem passado por inúmeras transformações, crescendo substancialmente nos últimos anos no Brasil, estimulando a instalação de novos empreendimentos hoteleiros, que ofereçam conforto e qualidade de serviços aos clientes.

O município de Bento Gonçalves - RS foi escolhido como foco da presente pesquisa, por ser um importante pólo moveleiro, vitivinícola e turístico da Serra Gaúcha.

Dados fornecidos pelo SHRBS (Sindicato de Hotéis, Restaurantes, Bares e Similares) da Serra Gaúcha apontam que, no período da pesquisa, a cidade de Bento Gonçalves contava com trinta e cinco estabelecimentos de hospedagem, entre hotéis e pousadas. Assim, em virtude do universo da pesquisa ser, de certa forma, pequeno, e para obter um levantamento de dados significativo, foi utilizada a integralidade das empresas em operação, existentes no município. No entanto, não foi possível estabelecer contato com três empresas e duas negaram-se a responder o questionário, por motivos internos, de sorte que a amostra foi composta por trinta empresas.

A ferramenta utilizada para fazer o levantamento dos dados foi um questionário inspirado no modelo de Silva (2000), composto por dezoito quesitos, contendo perguntas abertas e de múltipla escolha. A parte inicial do questionário buscava informações gerais da empresa, de forma que pudesse ser feita uma caracterização dos estabelecimentos. Na sequência, as perguntas foram direcionadas a responder o objetivo geral da pesquisa, ou seja, o levantamento dos métodos e técnicas de custeio e das informações contábeis em que os gestores dos hotéis de Bento Gonçalves baseiam as suas decisões.

Após a aplicação do questionário, obteve-se um índice de $43 \%$ de retorno, ou seja, treze empresas participaram efetivamente da pesquisa. O procedimento foi realizado de duas formas: por telefone e email. Inicialmente, através do contato por telefone, foi solicitada a autorização das empresas para o envio do formulário e a participação dos estabelecimentos na pesquisa, explicando os objetivos e os benefícios que o estudo poderia fornecer. Além disso, foi informado aos participantes que a pesquisa tinha caráter científico e que as respostas somente seriam divulgadas sob o aspecto global, uma vez que o formulário foi desenvolvido com o auxílio da ferramenta Google Drive, a qual fornece total anonimato ao participante, não sendo revelado, ao pesquisador, quem respondeu a pesquisa.

\subsection{Apresentação dos resultados}

Os dados obtidos com a amostra respondente foram tabulados em planilha eletrônica para posterior análise. $\mathrm{O}$ formulário de pesquisa iniciava abordando o enquadramento do estabelecimento quanto à categoria do estabelecimento: hotel ou pousada. Obteve-se um maior retorno de negócios classificados como pousadas, com 54\% em face de $46 \%$ de respondentes classificados na categoria hotéis.

Quando indagado a respeito do número de colaboradores, a média das respostas se situou em 12 funcionários por empresa, com maior e menor número de funcionários de 47 e 1, respectivamente. Essa diferença significativa pode ser justificada devido ao fato da pesquisa mesclar hotéis e pousadas de diferentes portes e características. 
A questão 3 referia-se ao número de unidades habitacionais do estabelecimento. Da amostra respondente, pode-se perceber que a quantidade variou de acordo com o tipo do estabelecimento. No entanto, os maiores números não são necessariamente somente de hotéis. Em pousadas, a maior capacidade de leitos é de 49, e a menor, de 3. Já em hotéis, a maior capacidade é de 140 quartos, e a menor, de 16.

A questão 4 tinha o objetivo de verificar a área construída de cada empresa. A partir das respostas, observou-se que a média da área construída de pousadas ficou em $446 \mathrm{~m}^{2}$, sendo a maior com $1.200 \mathrm{~m}^{2}$ e a menor com $55 \mathrm{~m}^{2}$. Já a média de hotéis ficou em $2.100 \mathrm{~m}^{2}$, no qual o maior possui $6.800 \mathrm{~m}^{2}$ e o menor $100 \mathrm{~m}^{2}$.

O foco da questão 5 não era conhecer o faturamento bruto anual das empresas, bem como o faturamento bruto médio anual do setor pesquisado e o porte das empresas que se submeteram à pesquisa. No entanto, esta pergunta foi preenchida apenas por $38 \%$ das empresas respondentes, o que impossibilitou alcançar totalmente o objetivo. Acredita-se que, por se tratar de uma questão mais estratégica, houve receio em revelar tais informações. Foi possível observar que, dentre as empresas que atenderam à solicitação de informações, o maior faturamento bruto anual foi de $\mathrm{R} \$ 4.000 .000,00$ e o menor, de $\mathrm{R} \$$ $26.000,00$.

Em seguida, na pergunta 6, questionou-se sobre a posição hierárquica do colaborador respondente da pesquisa na empresa submetida à investigação. Obteve-se um índice de $38 \%$ dos questionários respondidos diretamente pelo diretor da empresa, $23 \%$ por gerente intermediário, $8 \%$ pelo contabilista e $31 \%$ por colaboradores diversos.

Buscou-se verificar, através da questão 7, se as empresas fazem parte de alguma rede ou grupo de empresas, assim como conhecer em quais mercados as organizações estão inseridas. Os resultados mostraram que $92 \%$ são empresas independentes e familiares que atuam apenas na região de Bento Gonçalves - RS e apenas $8 \%$ pertencem a alguma rede nacional, sendo que nenhum dos respondentes se identificou como afiliado a alguma rede internacional.

A questão 8 tinha por objetivo conhecer qual a forma de serviço contábil que as empresas respondentes utilizam, na qual constatou-se que $85 \%$ terceirizam este processo com um escritório externo especializado em contabilidade, e $15 \%$ dispõe de um contabilista interno.

O foco da questão 9 era conhecer a função da pessoa responsável pela tomada de decisões sobre preços de venda dos produtos e serviços da empresa. Em 69\% dos respondentes, este processo fica a cargo do diretor, $23 \%$ do gerente e $8 \%$ para outros colaboradores. Por se tratar de uma decisão que reflete diretamente nas receitas das empresas, o contabilista não é responsável por este procedimento, apenas fornece informações para que a organização possa fundamentar sua decisão.

Na sequência, questionou-se qual o método de custeio utilizado pelo estabelecimento para fins de tomada de decisão, com o objetivo de comparar com resultados obtidos em outros estudos realizados no país e confrontar com o que a literatura indica para este fim. A partir dos resultados obtidos, observou-se que $46 \%$ das empresas pesquisadas já empregam o custeio variável e $8 \%$ utilizam o custeio baseado em atividades, ou seja, mais da metade dos respondentes utilizam algum método direcionado para a tomada de decisão. Na sequência, $15 \%$ ainda utilizam o custeio por absorção, enquanto que $31 \%$ ainda não utilizam nenhum método de custeio.

De acordo com Lima, Egito e Silva (2004), o custeio variável é o mais indicado para a tomada de decisão, pois fornece subsídios que servem tanto para o planejamento a longo prazo como para ações imediatas, já o custeio por absorção, quando utilizado para fins gerenciais, pode fornecer informações equivocadas, em virtude deste método agregar os custos fixos aos produtos e serviços dos empreendimentos, pois estes independem da taxa de ocupação. $\mathrm{O}$ custeio baseado em atividades também é 
indicado para tomada de decisões, em virtude de proporcionar uma melhoria nas decisões gerenciais, por ter maior precisão do custo real do produto ou serviço, sempre em busca da rentabilidade do negócio (MARTINS, 2009).

O foco da questão 11 era descobrir o motivo de $31 \%$ das empresas respondentes ainda não utilizarem algum método de custeio para fins de tomada de decisões. $\mathrm{Na}$ análise das respostas, foi possivel verificar que para $75 \%$ delas o processo está em fase de implantação e para $25 \%$ acreditam que não há necessidade, no momento, não sendo motivo desta não utilização a falta de conhecimento. Um fato importante é que alguns métodos de custeio não são aceitos pela legislação fiscal, também podendo ser este um dos motivos que um número significativo das empresas respondentes da pesquisa ainda não possuir um método de custeio específico para fins gerenciais.

A questão 12 era designada somente às empresas respondentes que empregam algum método de custeio, e questionava o uso de algum mecanismo de controle que fornece as informações de custos com agilidade para que o tomador de decisão possa fundamentar a sua escolha. Com base nas respostas obtidas, $56 \%$ pontuaram que possuem algum mecanismo de controle que fornece as informações de custo com agilidade, $11 \%$ também possuem mecanismo de controle, porém com pouca agilidade, e 33\% não possuem.

Margem de contribuição e ponto de equilíbrio são conceitos muito importantes para a gestão de uma empresa e foi este o foco da questão 13. O primeiro conceito diz respeito a quanto o produto contribui para cobrir os custos fixos, e o segundo refere-se ao ponto em que o total das vendas é igual ao total de despesas, não resultando em lucro e nem em prejuízo, mas apenas no equilíbrio. Da amostra respondente, $62 \%$ informa que possui conhecimento, $23 \%$ não possui, e $15 \%$ possui, mas somente de alguns produtos ou serviços.

Na questão seguinte, a de número 14, o objetivo era descobrir se o gestor disponibiliza de relatórios de custos de seus produtos e serviços, sejam fornecidos pelo sistema próprio ou pela contabilidade, para auxiliar o processo das tomadas de decisões e com qual frequência faz isso. Os resultados obtidos da amostra respondente demonstraram que $61 \%$ sempre faz uso desta ferramenta, $31 \%$ frequentemente e $8 \%$ raramente utilizam.

A utilização de um centro de custos para apurar os gastos departamentais era a pergunta da questão 15. O uso dessa ferramenta possibilita acompanhar o desempenho individual de cada setor da empresa, onde $62 \%$ da amostra respondente disse que sim, e $38 \%$ não utiliza.

Os custos indiretos precisam de uma base de rateio para serem atribuídos aos produtos e, desta forma, na questão 16 foi questionado qual é essa base de rateio utilizada por cada uma das empresas. A análise dos resultados obtidos demonstrou que $69 \%$ das empresas realizam o rateio de custos, $31 \%$ das quais apropriam-nos por departamento, $23 \%$ por apartamento, $15 \%$ por produto ou serviço. Os $31 \%$ restantes, informaram que os custos indiretos não são rateados.

O rateio dos custos indiretos é relacionado com o uso do custeio por absorção, e não com o custeio variável ou com o $\mathrm{ABC}$. Nos resultados obtidos da questão 10, apenas $15 \%$ das empresas afirmaram empregar o uso do custeio por absorção o que, estranhamente, contraria o resultado obtido nesta questão, em que $69 \%$ das empresas avaliadas possuem uma base de rateio de seus custos indiretos.

A formação do preço de venda era o objeto da questão 17. Nela, buscava-se apurar qual o critério utilizado pelo gestor do estabelecimento para definir o preço de venda de seus produtos e serviços. Foram consideradas todas as empresas que responderam o questionário, a fim de se obter um panorama completo. As respostas apontaram que $46 \%$ empregam o critério de custos, $31 \%$ utilizam o critério da demanda, $8 \%$ se baseiam pelo critério da concorrência, e $15 \%$ fazem um mix dos três critérios. 
E, para finalizar o questionário, a questão 18 fazia referência à importância das informações de custos para a gestão das empresas atualmente, e todos os casos responderam que consideram muito importante conhecer os custos dos produtos e serviços para obter os melhores resultados provindos de novas decisões. Apesar de todos considerarem muito importante, ao longo dos resultados obtidos, percebese que ainda há deficiências no uso correto dos métodos de custeio e das informações que a contabilidade de custos proporciona.

\subsection{Discussão dos resultados}

Nesta seção será realizada uma discussão e comparação dos resultados obtidos na presente pesquisa, com estudos semelhantes a presente pesquisa aplicados em outras regiões do país. Partindo dos resultados apresentados na questão referente aos métodos de custeio para fins gerenciais, tem-se que 69\% das empresas fazem uso de algum método de custeio, em que a maioria (46\%) dos respondentes utiliza o custeio variável, $15 \%$ empregam o custeio por absorção, e $8 \%$ o ABC.

Comparando estes valores com os outros estudos demonstrados na Tabela 1, pode-se verificar a predominância do uso do custeio variável na região Sul e Centro-Oeste do país, acompanhada pelo custeio por absorção e ABC. Já nas regiões Norte e Nordeste, o custeio por absorção apresenta-se na maioria dos casos quando se trata de fins gerenciais, seguida pelo custeio variável e ABC.

Tabela 1 - Comparativo dos métodos de custeio

\begin{tabular}{l|c|c|c}
\hline \multicolumn{1}{c|}{ Pesquisa } & Absorção & Variável & ABC \\
\hline Presente (Sul) & $15,0 \%$ & $46,0 \%$ & $8,0 \%$ \\
\hline Vieira e Souza (2005) (Sul) & $0,0 \%$ & $80,0 \%$ & $20,0 \%$ \\
\hline Lunkes (2009) (Sul) & $5,0 \%$ & $45,0 \%$ & $50,0 \%$ \\
\hline $\begin{array}{l}\text { Lima, Egito e Silva (2004) (Norte e } \\
\text { Nordeste) }\end{array}$ & $62,5 \%$ & $25,0 \%$ & $6,2 \%$ \\
\hline Silva (2000) (Nordeste) & $67,9 \%$ & $25,9 \%$ & $5,4 \%$ \\
\hline $\begin{array}{l}\text { Caldas, Caldas e Silva (2006) } \\
\text { (Nordeste) }\end{array}$ & $77,0 \%$ & $20,0 \%$ & $3,0 \%$ \\
\hline Leitão e Silva (2006) (Nordeste) & $72,1 \%$ & $24,5 \%$ & $3,4 \%$ \\
\hline Rosa e Morgan (2006) (Centro-Oeste) & $0,0 \%$ & $75,0 \%$ & $0,0 \%$ \\
\hline
\end{tabular}

Fonte: Elaborado pelos Autores, com base em Vieira e Souza (2005), Lunkes (2009), Lima, Egito e Silva (2004), Silva (2000), Caldas, Caldas e Silva (2006), Leitão e Silva (2006) e Rosa e Morgan (2006).

Em relação ao conhecimento sobre margem de contribuição e ponto de equilíbrio, obteve-se a partir da amostra respondente que 62\% afirmam conhecer essas métricas para todos os produtos e serviços, $15 \%$ só conhecem para alguns dos produtos e serviços, e $23 \%$ desconhecem totalmente.

Como exposto na Tabela 2, confrontando estes resultados com os apresentados por Lima, Egito e Silva (2004) e Leitão e Silva (2006), percebe-se certa semelhança, destacando maioria para aqueles que conhecem a margem de contribuição e ponto de equilíbrio de todos os seus serviços, com 56,3\% e 52,4\% respectivamente, com $15,6 \%$ e 14,3\% conhecem somente de alguns serviços, diferentemente do estudo 
realizado por Silva (2000), em que apenas 32,1\% afirmaram conhecer. No entanto, só quem utiliza o custeio variável encontra a margem de contribuição e, consequentemente, o ponto de equilíbrio.

Tabela 2 - Comparativo margem de contribuição e ponto de equilíbrio

\begin{tabular}{l|c|c}
\hline \multicolumn{1}{c|}{ Pesquisa } & Todos os produtos & Somente de alguns \\
\hline Presente (Sul) & $62,0 \%$ & $15,0 \%$ \\
\hline Lima, Egito e Silva (2004) (Norte/Nordeste) & $52,4 \%$ & $14,3 \%$ \\
\hline Leitão e Silva (2006) (Nordeste) & $56,3 \%$ & $15,6 \%$ \\
\hline Silva (2000) (Nordeste) & $32,1 \%$ & - \\
\hline
\end{tabular}

Fonte: Elaborado pelos Autores com base em Lima, Egito e Silva (2004), Leitão e Silva (2006) e Silva (2000).

Conforme já apresentado na seção anterior, na presente pesquisa apenas $46 \%$ dos respondentes empregam este método, o que confirma que a ferramenta não está sendo utilizada corretamente ou que o respondente se equivocou ao responder.

Concomitantemente a este fato, quando questionada a forma de rateio dos custos indiretos, $69 \%$ afirmaram fazer o rateio, seja por departamento, apartamento ou serviço. No entanto, a alocação dos custos indiretos a partir de uma base de rateio está relacionada ao uso do custeio por absorção, e somente $15 \%$ das empresas empregam este método.

Com base no uso de centro de custos para gastos departamentais na presente pesquisa, obteve-se um percentual positivo de $62 \%$ contra 38\% negativo. Na investigação de Lima, Egito e Silva (2004), o resultado foi de que $78,13 \%$ utilizam centro de custos e 21,88 não utilizam. Resultado semelhante foi encontrado por Silva (2000), no qual 51,86\% responderam que sim e 46,91\% que não.

$\mathrm{Na}$ análise dos resultados da questão sobre a forma de rateio dos custos indiretos, $31 \%$ informou que faz o rateio por departamento, $23 \%$ por apartamento e $15 \%$ por produto e serviço, sendo que $31 \%$ responderam não realizar este rateio.

Os resultados obtidos nos estudos empíricos de Silva (2000), Lima, Egito e Silva (2004) e Leitão e Silva (2006) assemelham-se com o resultado da presente pesquisa, pois, na maioria dos casos, o rateio ocorre por departamentos, e, na sequência, está o rateio por número de apartamentos e por produtos e serviços.

No que diz respeito à formação do preço de venda dos produtos e serviços, obteve-se com a amostra respondente que $46 \%$ praticam seu preço de acordo com os custos do produto ou serviço, $31 \%$ com base na demanda do mercado, $8 \%$ na concorrência, e $15 \%$ afirmam fazer um mix dos três critérios para definir seu preço.

$\mathrm{Na}$ Tabela 3 pode-se observar que no estudo elaborado por Vieira e Souza (2005), 50\% dos respondentes definem o preço de venda a partir do preço de mercado. Já para Lunkes (2009), a maioria, com $31 \%$, respondeu que tomam por base o preço da concorrência, seguidos pelo preço de mercado e pelo mix dos critérios com $27 \%$ cada, e pelo critério dos custos, com apenas $15 \%$.

Em Machado, Machado e Holanda (2006), a predominância foi do mix dos elementos de demanda e custos com $71 \%$. O critério de custos possui a maioria na pesquisa elaborada por Oliveira et al (2008), juntamente com o mix de demanda e custo, em que aparecem igualados em $40 \%$, seguido pelo critério da demanda com $20 \%$.

No estudo de Caldas, Caldas e Silva (2006), em primeiro lugar está o critério de custos com $60 \%$, em segundo, o critério da demanda com $30 \%$ e em terceiro, o mix de custos e demanda com apenas $3 \%$. 
Na região centro-oeste, Rosa e Morgan (2006), concluíram que a base de cálculo para $63 \%$ da amostra é o preço do concorrente, seguido pelo critério dos custos, com $27 \%$.

Tabela 3 - Comparativo dos critérios de formação do preço de venda

\begin{tabular}{|c|c|c|c|c|}
\hline Pesquisa & Custos & Demanda & Concorr. & Mix \\
\hline$\overline{\text { Presente (Sul) }}$ & $46,0 \%$ & $31,0 \%$ & $8,0 \%$ & $15,0 \%$ \\
\hline Vieira e Souza (2005) (Sul) & - & $50,0 \%$ & - & - \\
\hline $\begin{array}{l}\text { Lunkes (2009) (Sul) } \\
\text { (Sula }\end{array}$ & $15,0 \%$ & $27,0 \%$ & $31,0 \%$ & $27,0 \%$ \\
\hline $\begin{array}{l}\text { Machado, Machado e Holanda (2006) } \\
\text { (Nordeste) }\end{array}$ & - & - & - & $71,0 \%$ \\
\hline Oliveira et al (2008) (Nordeste) & $40,0 \%$ & $20,0 \%$ & - & $40,0 \%$ \\
\hline $\begin{array}{l}\text { Caldas, Caldas e Silva (2006) } \\
\text { (Nordeste) }\end{array}$ & $60,0 \%$ & $30,0 \%$ & - & $3,0 \%$ \\
\hline Rosa e Morgan (2006) (Centro-Oeste) & $27,0 \%$ & - & $63,0 \%$ & - \\
\hline
\end{tabular}

Fonte: Elaborado pelos Autores com base em dados de pesquisas de Vieira e Souza (2005), Lunkes (2009), Machado, Machado e Holanda (2006), Oliveira et al (2008), Caldas, Caldas e Silva (2006) e Rosa e Morgan (2006).

Ao analisar os dados demonstrados, pode-se concluir que as empresas hoteleiras da região Sul e as empresas de serviço da região Centro-Oeste fornecem um suporte mais adequado à tomada de decisão que as similares das regiões Norte e Nordeste, em virtude da predominância do uso do custeio variável.

Há uma grande variação nos resultados encontrados a respeito da formação do preço de venda em pesquisas aplicadas, em virtude de existir uma relação entre os custos, demanda e a concorrência. A média dos resultados dos estudos descritos anteriormente ficou de 31,1\% para o critério de custos, 26,2\% para a demanda, 16,9\% para a concorrência, e 25,8\% para o mix destes três critérios. Para alguns autores, o mais correto é fazer uma combinação destes três elementos e, a partir disso, elaborar o preço de venda.

\section{CONCLUSÃo}

O ambiente competitivo existente atualmente entre as empresas tem compelido a busca por alternativas que garantam a sobrevivência e consolidação das empresas no mercado.

A partir do aprimoramento das práticas gerenciais, as informações relativas aos custos dos produtos e serviços tornaram-se elemento diferencial de análise, imprescindível para o entendimento dos recursos consumidos e tomadas de decisões organizacionais.

A partir dos resultados obtidos através do levantamento de dados realizado no setor hoteleiro de Bento Gonçalves - RS, constatou-se que o método de custeio predominante foi o custeio variável, adotado por $46 \%$ das empresas investigadas e que, segundo referências literárias, é tido como o mais adequado para o suporte à tomada de decisão, em virtude de atribuir ao custo do produto somente os custos e despesas variáveis do produto em questão.

Quanto aos fatores que as empresas levam em conta na formação do preço de venda de seus produtos e serviços, $46 \%$ da amostra respondente informou utilizar o critério dos custos, que caracteriza-se pelo acréscimo de um percentual, chamado markup, sobre o custo do produto, destinado a cobrir os gastos extras. 
Estudos apontam que a forma mais apropriada de se definir o preço que seu serviço custará é a partir de uma combinação de elementos de custos, demanda e concorrentes.

Os resultados obtidos a partir da pesquisa revelaram que todos os respondentes acreditam ser de muita importância as informações de custos para o processo gerencial em função de um mercado competitivo e exigente, mesmo sem demonstrar possuir um entendimento profundo sobre o assunto. No entanto, há oportunidade de crescimento na área de custos, pois $46 \%$ das empresas pesquisadas ainda não possuem um controle de custos voltado para a gestão de decisões organizacionais. Este número significativo pode estar relacionado ao fato de que nem todos os métodos de custeio adequados para a tomada de decisão são aceitos legalmente pelo fisco, ou, ainda, ao fato dos custos de implantação e controle contínuo, em paralelo ao método legal, serem relativamente altos, em que os benefícios do método não compensarão todos os custos da empresa.

Considerando o objetivo proposto, pode-se concluir que o mesmo foi atingido. De modo geral, a maioria das empresas da amostra respondente fornece um suporte adequado ao processo decisório, em virtude do uso do custeio variável, ainda que, de certa forma, limitado, assim como um critério apropriado para a formação do preço de venda.

\section{REFERÊNCIAS}

BEUREN, I.M. Gerenciamento da informação: um recurso estratégico no processo da gestão empresarial. 2.ed. São Paulo: Atlas, 2000.

BEUREN, I. M. Como elaborar trabalhos monográficos em contabilidade: teoria e prática. 2.ed. São Paulo: Atlas, 2004.

BORNIA, A.C. Análise gerencial de custos: aplicações em empresas modernas. Porto Alegre: Bookman, 2002.

CALDAS, P.D’O.A.; CALDAS, E.A.P.; SILVA, J. D. G. da. Avaliação da estrutura da gestão de custos no setor de hospedagem dos hotéis nordestinos: um estudo nos estados do Rio Grande do Norte, Paraíba e Pernambuco. Revista Acadêmica Observatório de Inovação do Turismo, v. 1, n. 3, 2006.

CREPALDI, S.A. Curso básico de contabilidade de custos. 5.ed. São Paulo: Atlas, 2010.

ECKERT, A. Marketing Virtual: conduzindo um empreendimento on-line ao sucesso. Curitiba: Prismas, 2017.

GIL, .C. Como elaborar projetos de pesquisa. 4.ed. São Paulo: Atlas, 2002.

IBRACON-Instituto Brasileiro de Contadores. Custo como ferramenta gerencial. São Paulo: Atlas, 1995.

KONRAHT, J.M.; SOUTES, D. O.; ALENCAR, R.C. A relação entre a governança corporativa e o alisamento de resultados em empresas brasileiras. Revista Contabilidade e Controladoria, v. 8, n. 1, 2016.

LEITÃO, C. R. S.; SILVA, J.D. G. da. Gestão de custos em hotéis: uma pesquisa sobre a utilização do custeio variável no setor hoteleiro do nordeste brasileiro. In: Congresso USP de Controladoria e Contabilidade, 6, 2006, São Paulo. Anais eletrônicos. São Paulo: USP, 2006, p. 1-14.

LEONE, G.S. G. Custos: planejamento, implantação e controle. 3.ed. São Paulo: Atlas, 2000. 
LIMA, G.A.S.F. de; EGITO, M. O.T.do; SILVA, J.D. G.da. Utilização de informações de custos no processo gerencial: estudo comparativo entre a hotelaria do estado do Rio Grande do Norte e a região nordeste, sob a ótica de gestão econômico-financeira. Contabilidade \& Finanças, v. 15, p. 106-116, 2004.

LUNKES, R.J. Informação de custos: um estudo em empresas hoteleiras na cidade de Florianópolis - SC. Turismo em Análise, v. 20, n. 2, p. 345-368, 2009.

MACHADO, M.A.V.; MACHADO, M.R.; HOLANDA, F. M.de A. Análise do processo de formação do preços do setor hoteleiro da cidade de João Pessoa/PB: um estudo de caso exploratório. Revista Acadêmica Observatório de Inovação do Turismo, v. 1, n. 3, 2006.

MARTINS, E. Contabilidade de custos. 9.ed. São Paulo: Atlas, 2009.

OLIVEIRA, E.C.de et al.. Utilização da gestão de custos para tomada de decisão: um estudo em hotéis de Porto de Galinhas no município de Ipojuca - PE. In: Congresso Brasileiro de Contabilidade, 18, 2008, Gramado. Anais eletrônicos. Gramado: CFC, 2008.

RICHARDSON, R.J. Pesquisa social: métodos e técnicas. 3.ed. São Paulo: Atlas, 1999.

ROSA, M. de S.; MORGAN, B. F. Custos em empresas prestadoras de serviços: o conceito de objeto de custo e a realidade das empresas. Contabilidade Vista \& Revista, v. 17, n. 4, p. 97-111, 2006.

SANTOS, J. J.dos. Contabilidade e análise dos custos. 6.ed. São Paulo: Atlas, 2011.

SILVA, J.D. G.da. Investigação da prática da gestão econômica na atividade hoteleira. Tese (Doutorado)-FEA/USP. São Paulo: 2000.

TRIPODI, T.; FELLIN, P.; MEYER, H.J. Análise da pesquisa social: diretrizes para o uso de pesquisa em serviço social e ciências sociais. 2.ed. Rio de Janeiro: Francisco Alves, 1981.

VIEIRA, W. Q.l; SOUZA, M.J. B.de. Gestão de custos nos hotéis de lazer da região sul do Brasil. Turismo - Visão e Ação, v. 7, n. 3, p. 427-438, 2005.

ZANELLA, L.C. Administração de custos em hotelaria. 4.ed. Caxias do Sul: Educs, 2010. 